\title{
The Simulation of Mean Radiant Temperature in Outdoor Conditions: A review of Software Tools Capabilities
}

\author{
Emanuele Naboni ${ }^{1}$, Marco Meloni ${ }^{1}$, Chris Mackey $^{2}$, Jerome Kaempf ${ }^{3}$ \\ ${ }^{1}$ KADK, Copenhagen, Denmark \\ ${ }^{2}$ Ladybug Tools, USA \\ ${ }^{2}$ EPFL, Switzerland
}

\begin{abstract}
Due to population growth and recent urbanisation trends, outdoor human comfort is becoming an essential parameter to assess the quality of the urban microclimate. In the last years, several tools were developed in to model outdoor human comfort, and each of them makes different physical assumptions for the calculation of the Mean radiant temperature (MRT), one of the most critical parameters influencing outdoor thermal comfort. This paper studies how CitySim Pro, ENVI-met, RayMan, Grasshopper plug-ins Ladybug Tools and Autodesk CFD, use different assumptions and equations to calculate MRT.
\end{abstract}

\section{Introduction}

Due to rapid and intensified urbanisation trends, new attention to the conditions of comfort and liveability of cities is given. People's thermal comfort is one of the factors that affect the fruition of urban spaces like streets, plazas and parks (Thorsson et al., 2014; Givoni et al., 2003). How the built environment alters local microclimates is widely studied (ONU 2014, Hoppe 2002), with the challenge of modelling pedestrians exposure to varying thermal conditions (Givoni et al., 2003). Whatever methods is used to model outdoor microclimates (ASCE, 2004, Epstein et al., 2006), these require the study of air temperature, mean radiant temperature (MRT), air velocity and relative humidity (Coccolo et al., 2016). Among these, MRT is one of the key parameters affecting outdoor thermal comfort conditions (Mayer, 1993, Lai et al., 2017). Indices as Predicted Mean Vote (PMV), Physiologically Equivalent Temperature (PET) and Universal Thermal Climate Index (UTCI) (Park S et al., 2014) includes MRT. In certain climates, especially non windy ones, MRT is the key factor governing human energy balance and thermal comfort (Chatzidimitriou and Yannas, 2017, Mayer et al., 1987, Coccolo et al., 2016, Mauree et al., 2017, 2019, Naboni et al., 2019). MRT has thus been proposed as a metric to analyse the impact of weather and climate on people's health (Thorsson et al., 2014), since it shows a very considerable spatial variation over short distances (Lindberg et al., 2013, Lee and Naboni, 2017). Accurate information on MRT is thus key. Several simulation tools were developed and refined to simulate the 3D radiation field in urban settings that affects MRT (Kantor et al., 2011, Naboni et al., 2017). In previous research about outdoor microclimate and MRT (Naboni et al., 2017, Coccolo et al., 2017) it is observed that different tools use different equations to simulate it. Revealing the capabilities and the limitations of the used equations by each of the available tools is thus the aim of the paper.

\section{Methodology}

It is essential to understand how simulation tools define their radiation model and how this is accurate. This study thus reviews simulation tools equations and physical modelling assumptions in the calculation of MRT. The work is divided into the description of the analysis of MRT, focusing on the physical description; the calculation (formulas) and the estimation of MRT from physical measurements. Following it is described the determination of MRT operated by the following software tools: CitySim Pro; ENVI-met; RayMan; Ladybug Tools; Autodesk CFD. A discussion that highlights the capabilities and the limitation of each of the tools closes the article.

\section{Background on MRT}

The MRT, is defined, in relation to a given person in a given environment, as the uniform temperature of a fictive black-body radiation enclosure with emission coefficient $\varepsilon=1$, which would result in the same net radiation energy exchange with the subject as the real more complex radiation environment (ASHRAE, 2001). The following radiation components are of importance, as presented in Figure 1: The direct, diffuse and reflected shortwave radiations (wavelength $\lambda=0.3-3 \mu \mathrm{m}$ ), the atmosphere and the built and natural environment (ground, tree and surrounding surfaces) and the longwave radiation (wavelength $\lambda$ $=3-100 \mu \mathrm{m}$ ). The significance of solar and terrestrial radiation fluxes depends on the time and location conditions. During night conditions, radiation exchanges consist only of longwave components. By contrast, the shortwave radiation has a role only in sunlight hours. Longwave radiation fluxes occupy a higher per cent of the human field of view, while the shortwave radiation fluxes affect $30 \%$ of the radiation budget (Ali Toudert, 2005).

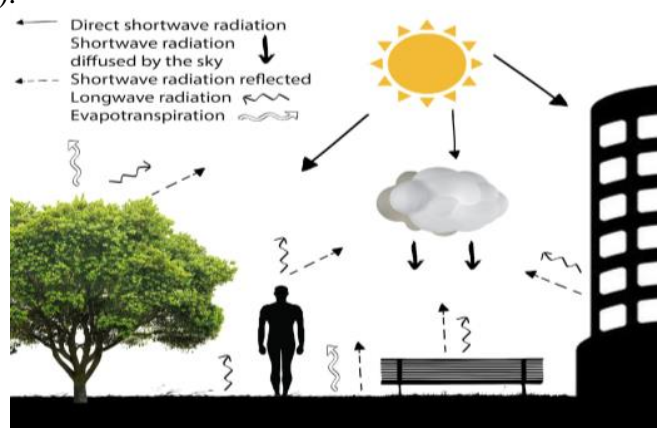

Figure 1: Relevant radiation fluxes and urban entities on the determination of outdoor MRT.

\section{Mean Radiant Temperature Calculation}

The calculation of MRT is based on the determination of the radiation profiles of the surrounding surfaces and the visible section of the sky. Therefore, the temperatures of all the surrounding surfaces have to be known. The pedestrian posture also has to be known, as the perceived MRT varies with the position and orientation of the body. The absorptivity and emissivity of the human outer surfaces have an impact and needs to be defined. Following the MRT calculation suggested by Fanger (1972), shortwave and longwave radiation fluxes have to be weighted with their respective angle factors and summarise to determine the energy amounts reaching the human body. The energy fluxes reaching the human body are absorbed according to the shortwave absorption coefficient $a_{k}$ (generally assumed 
to be 0.7 for medium clothing with light skin), and the longwave absorption coefficient $a_{i}$ (generally 0.97 ) that equals the emission coefficient of the clothed human body $\left(\varepsilon_{\mathrm{p}}\right)$ in accordance with Kirchoff's law. The radiation flux $S_{S t r}\left(\mathrm{~W} / \mathrm{m}^{2}\right)$ absorbed by the human body is described as follow (Kantor et al. 2011):

$$
S_{S t r}=a_{l} \cdot \sum_{i=1}^{n} F_{i} \cdot E_{i}+a_{k} \cdot \sum_{i=1}^{n} F_{i} \cdot D_{i}+a_{k} \cdot f_{p} \cdot I^{*} \quad\left[\mathrm{~W} / \mathrm{m}^{2}\right]
$$

where $a_{l}$ and $a_{k}$ are the longwave and shortwave radiation absorption coefficient, $F_{i}$ is the "view factor" describing the solid angle proportions of the surrounding surfaces, $E_{i}$ and $D_{i}$ are the emitted longwave and diffuse sky and reflected shortwave radiations, $f_{p}$ is the surface projection factor, whilst $I^{*}$ id the direct shortwave radiation. According to the previously defined radiation energy gain of the human body and the definition of MRT (ASHRAE 2001), the formula can be defined as (Kantor et al. 2011)

$$
T_{m r t}=\sqrt[4]{\frac{S_{S t r}}{\varepsilon_{p} \cdot \sigma}}[\mathrm{K}]
$$

where $\varepsilon_{p}$ is the emission coefficient of the clothed human body and $\sigma$ is the Stefan-Boltzmann constant $(\sigma=5.67 \cdot 10-8$ $\mathrm{W} / \mathrm{m}^{2} \mathrm{~K}^{4}$ ).

\section{The determination of outdoor MRT}

As the flux densities are considerably diverse, spatially and temporally, determine the MRT in urban environments with complex surface conformations is still a challenge for the practitioner's field. The definition of the surrounding surfaces properties, solid angle proportions, and the measurement of short and longwave radiation fluxes reaching the human body are the main issues in the determination of MRT. As MRT is not a physically measurable entity, all the discussion about its determination refer to the different methods used to arrive at a reasonable level of approximation in its calculation.

The research of Johansson et al. (2014) underlines the necessity to adopt a standard criterion in the study of outdoor microclimates (Standard ISO 7726). Indoor measurement tools are not reliable if used for outdoor environment applications, particularly for MRT measurements, which are significantly affected by direct solar radiation. Johansson studied MRT outdoor measurements referring to Mayer and Hoppe's studies (1987) and German Guideline VDI 3787 (2008). He specifies that MRT calculation I have to be calibrated on-site with the integral radiation technique described by Thorsson et al. (2007). According to Standard VDI (1998), accurate methods to determine MRT are based on integral radiation measurements. Among them, the most accurate method is based on measurements taken by a combination of pyranometers and pyrgeometers (Hoppe, 1992). The pyranometer is used to measure the shortwave radiation fluxes. The pyrgeometer is used to measure the longwave domain. The mean radiation flux density $S_{S t r}\left(\mathrm{~W} / \mathrm{m}^{2}\right)$ absorbed by the body is calculated as:

$$
S_{S t r}=\sum_{i=1}^{6} W_{i} \cdot\left(a_{k} \cdot K_{i}+a_{i} \cdot L_{i}\right) \quad[\mathrm{W} / \mathrm{m} 2]
$$

where $W_{i}$ are the weighting factors corresponding to the direction of the measurements, which for standing or walking person are assumed to be 0.22 for radiation fluxes coming from North, South, West and East and 0.06 for radiation fluxes coming from above and below; $a_{k}$ and $a_{i}$ are the body absorption coefficients of the clothed body for shortwave and longwave radiations. $K_{i}$ Also, $L_{i}$ are the measured six individual shortwave and longwave radiation fluxes. The MRT is calculated according to Stefan-Boltzmann's law as described in Equation 2. The most important advantage of this method is the capability to separate measure of the shortwave and longwave radiation fields, which allows taking into account the different absorption coefficients and the consequent different importance in the radiation energy budget. A second method of measuring the MRT is based on the utilisation of a globe thermometer. Initially developed for indoor conditions, it was further used for outdoor measurements due to its easier accessibility compared to pyranometer and pyrgeometer measurements method (Thorsson et al., 2007). The globe thermometer may vary in dimensions and material properties. It measures MRT according to the following equation:

$$
T_{m r t}=\sqrt[4]{\left(T_{g}+273.15\right)^{4}+\frac{h_{c g}}{\varepsilon \cdot d_{g}^{0.4}} \cdot\left(T_{g}-T_{a}\right)} \quad[\mathrm{K}]
$$

where $T_{g}$ is the globe temperature, $T_{a}$ is the air temperature, $\varepsilon$ is the emissivity of the sphere, $d_{g}^{0.4}$ is the diameter of the sphere, and $h_{C g}$ is the globe's mean convection coefficient. In outdoor environments, where the radiant environment constantly varies in not homogeneous conditions, the globe thermometer is less suitable than the pyranometer/pyrgeometer measurements. Some of the main issues are recognized in the difficulties to approximate the standing position of the human body due to its spherical shape, the impossibility to take into account the different longwave and shortwave radiations absorption coefficients, and uncertainty results due to its long time in reaching the equilibrium in outdoor conditions (Kantor et al., 2011; Thorsson et al., 2007).

\section{The determination of outdoor MRT by simulation tools}

Without sophisticated and time-consuming on-site measurement procedures, the MRT can be obtained by modelling the whole radiation field with simulation models approaches. Following the increasing interest in outdoor comfort analysis, few modelling tools are today available for predicting microclimatic parameters as MRT, but the potential users are confronted with the dilemma of choosing a suitable simulation tool. Hence, a new understanding of simulation tools physical assumptions is necessary to select the tool that better suits design needs. In the last three years, several simulation tools have been developed to simulate the 3D radiation field in urban settings and calculate the MRT. Among them, CitySim Pro, ENVI-met V.4, RayMan 1.2, Grasshopper plug-ins Ladybug Tools (Honeybee 0.0.60, Ladybug 0.0.63, Butterfly 0.0.04) and Autodesk CFD 2016 are the simulation tools based on 3D models that have been selected for the present study. In the following paragraphs, their MRT equations and physical assumption are compared and discussed. CitySim Pro (Robinson et al., 2009) predicts energy fluxes at various scales. The energy model coded in the tool is validated according to the Building Energy Simulation Test (BESTEST), as well as against EnergyPlus (Coccolo et al., 2013). The MRT calculation within CitySim is based on the integral radiation measurement defined by Hoppe (Coccolo et al., 2017):

$$
T_{m r t}=\sqrt[4]{\left(\frac{s_{m}}{\left(\varepsilon_{p} \sigma\right)}\right)} \quad[\mathrm{K}
$$

where $S_{m}(\mathrm{~W} \cdot \mathrm{m}-2)$ is the mean radiant flux density, $\varepsilon_{p}(-)$ is the emissivity of human $\mathrm{n}$ body and $\sigma$ is the Stefan- Boltzmann constant; a standard value of 0.97 is assumed for the emissivity. The mean radiant flux density $S_{s t r}$ corresponds to the sum of the short and longwave radiation impinging on each facade, multiplied by the corresponding angular weighting factor. Each 
distinct contribution is weighted by the corresponding absorption coefficient (e.g. 0.7 for the short wave radiation and 0.97 for the long wave radiation. Longwave and shortwave radiation exchanges are calculated in accordance with their respective customizable absorption coefficient. The temperature of each building surface viewed from the face of a target point is calculated as a weighted temperature, where the weight is defined by how much surrounding surfaces are viewed by the face of a given point.

ENVI-met simulates the surface-plant-air interactions in an urban environment (Bruse, 2004). It is validated and compared to onsite measurements (Jeong et al. 2015). ENVI-met calculation of MRT is defined by the following equation (Bruse 1999):

$$
T_{m r t}=\left[\frac{1}{\sigma} \cdot\left(E_{t}(z) \cdot \frac{a_{k}}{\epsilon_{p}} \cdot\left(D_{t}(z)+I_{t}(z)\right)\right)\right]^{0.25}[\mathrm{~K}]
$$

The surrounding environment consists of the building surfaces, the atmosphere and the ground surface. All radiation fluxes, i.e. direct irradiance $\mathrm{I}_{\mathrm{t}}(\mathrm{z})$, diffuse and diffusely reflected solar radiation $\mathrm{D}_{\mathrm{t}}(\mathrm{z})$ as well as the total long-wave radiation fluxes $\mathrm{E}_{\mathrm{t}}(\mathrm{z})$ from the atmosphere, ground and walls, are taken into account (Ali Toudert, 2005). At street level, $\mathrm{E}_{\mathrm{t}}(\mathrm{z})$ is assumed to be originated $50 \%$ from the upper hemisphere (sky and buildings) and $50 \%$ from the ground. This approximation is valid only at street level because of the influence of longwave radiation of the ground decrease with the increased height. The temperature of each building surface viewed from the face of a target point is calculated as a weighted temperature, where the weight is defined by how much surrounding surfaces are viewed by the face of a given point.

RayMan is a human-bio-meteorological tool based on radiant fluxes and thermophysiological indices (Matzarakis et al., 2009). RayMan outputs are validated against on-site measurements (Matzarakis, 2002). Rayman calculates the MRT from the Stefan-Boltzmann radiation law (Matzarakis, 2006):

$$
T_{m r t}=\sqrt[4]{\frac{S_{S t r}}{a_{l} \cdot \sigma}}
$$

with

$$
S_{\text {str }}=a_{k} \cdot \sum_{i=1}^{6} K_{i} \cdot F_{i}+a_{l} \cdot \sum_{i=1}^{6} L_{i} \cdot F_{i} \quad\left[\mathrm{~W} / \mathrm{m}^{2}\right]
$$

where $\mathrm{S}_{\text {str }}\left(\mathrm{W} \cdot \mathrm{m}^{-2}\right)$ is the mean radiant flux density, $\mathrm{K}_{\mathrm{i}}(-)$ is the short-wave radiation fluxes $(\mathrm{i}=6), \mathrm{L}_{\mathrm{i}}\left(\mathrm{W} \mathrm{m}^{-2}\right)$ is the longwave radiation fluxes $(\mathrm{i}=6), \mathrm{F}_{\mathrm{i}}(-)$ is the angle factors between a person and the surrounding surfaces (i=6), $a_{k}(-)$ is the absorption coefficient for shortwave radiation (standard value 0.7$), a_{i}(-)$ is the absorption coefficient for long-wave radiation (standard value 0.97$)$ and $\sigma$ is the Stefan-Boltzmann constant $\left(5.67 \times 10^{-}\right.$ $\left.{ }^{8} \mathrm{Wm}^{-2} \mathrm{~K}^{-4}\right)$. The radiation fluxes are calculated by model approaches, which include air temperature and air humidity, degree of cloud cover, air transparency and time of the day of the year.

Ladybug Tools (Roudsari and Pak 2013) are plugins for Grasshopper, which include a series of components for the simulation of the outdoor thermal environment. MRT is simulated by first computing a first longwave MRT based on surface temperatures calculated with the EnergyPlus simulation engine. View factors of every surface are calculated with the ray-tracing capabilities of the Rhino 3D modelling engine. The MRT calculation is based on the following formula (Mackey et al. 2017):

$$
T_{m r t}=\left[\sum_{i=1}^{N} F_{i} \cdot T_{i}^{4}\right]^{1 / 4}[\mathrm{~K}]
$$

(9)

where $\mathrm{F}$ is the fraction of the spherical view occupied by a given indoor surface and $\mathrm{T}$ is the temperature of the surface. The temperature of each building surface viewed from the face of a target point is calculated as a weighted temperature, where the weight is defined by how much surrounding surfaces are viewed by the face of a given point. The outdoor calculation takes into account the sky temperature and the consequent longwave loss to the sky. The longwave temperature of the sky $\left(\mathrm{T}_{\text {sky }}\right)$ is defined following the Man-Environment Heat Exchange Model (Blazejczyk, 1992) as stated by Mackey (Mackey et al. 2017):

$$
T_{s k y}=\frac{L_{a}}{\left(\varepsilon_{p} \cdot\right)^{1 / 4}} \quad[\mathrm{~K}] \quad(10)
$$

where $\mathrm{La}_{\mathrm{a}}\left(\mathrm{W} / \mathrm{m}^{2}\right)$ is the downwelling longwave radiation from the sky, $\varepsilon_{\mathrm{p}}$ is the emissivity of the human body assumed to be 0.95 , and $\sigma$ is the Stefan-Boltzmann constant $\left(5.667 \times 10^{-8}\right)$. The calculated longwave MRT is then adjusted to account for shortwave solar radiation that falls on people using the SolarCal model, which is a part of ASHRAE-55 thermal comfort standard (Arens et al. 2015). The SolarCal model is used to produce an effective radiant field (ERF) and a corresponding MRT delta with the following formula:

$$
E R F_{\text {solar }}=\left(0.5 \cdot f_{\text {eff }} \cdot f_{s v v} \cdot\left(I_{\text {diff }}+I_{T H} \cdot R_{f l o o r}\right)+\frac{A_{p} \cdot f_{\text {bes }}{ }^{l} \text { dir }}{A_{D}}\right) \cdot\left(\frac{a_{s w}}{a_{l w}}\right)\left[\mathrm{W} / \mathrm{m}^{2}\right]
$$

where $f_{\text {eff }}$ is the fractional of the body that can radiate heat $(0.725$ for a standing person), $f_{s v v}$ is the sky view factor, and $f_{\text {bes }}$ is a $1 / 0$ value computed by tracing the sun vector, which indicates if direct radiation is falling on the person. Idiff is the diffuse sky radiation, $I_{T H}$ is the global horizontal radiation, and $I_{d i r}$ is the direct radiation taken from TMY data. $A_{p}$ and $A_{D}$ are geometry coefficients of the human body, which are computed based on sun altitude and azimuth. $R_{\text {floor }}$ is the reflectivity of the ground (assumed to be 0.25 by default though this can be changed), and the $\alpha$ values refer to the absorptivity and reflectivity of the person's clothing (Mackey et al., 2017). The ERF is converted into an MRT delta using the following equation:

$$
E R F_{\text {solar }}=f_{\text {eff }} \cdot h_{r}\left(M R T-T_{L W}\right) \quad\left[\mathrm{W} / \mathrm{m}^{2}\right]
$$

where $f_{\text {eff }}$ is the fractional of the body that can radiate heat $(0.725$ for a standing person), $\mathrm{h}_{\mathrm{r}}$ is the radiation heat transfer coefficient $\left(\mathrm{W} / \mathrm{m}^{2} \mathrm{~K}\right)$, and $\mathrm{T}_{\mathrm{Lw}}$ is the base longwave MRT temperature $\left({ }^{\circ} \mathrm{C}\right)$. Autodesk CFD (Autodesk, 2016a) provides computational fluid dynamics and thermal simulations. It calculates outdoor comfort indexes based on Finite Element Methods (FEM), including MRT. Autodesk CFD thermal model is not validated for outdoor applications. It calculates the MRT with the following equation (Autodesk 2017):

$$
M R T_{i}=\sum_{J=1}^{n} F_{i j} \cdot T_{j} \quad[\mathrm{~K}]
$$

where $F_{i j}$ is the view factors and $T_{j}$ is the temperature of face $j$. It is a weighted temperature based on how much view space face $\mathrm{j}$ is taking when viewed from face i. The Autodesk CFD radiation model is a diffuse grey body model where directional dependencies and radiation wavelength are not considered (Autodesk 2017).

\section{Software review}

In order to be further compared, MRT physical assumptions of each simulation tool are presented in diagrams. The definition of the human body is an essential parameter in MRT 
determination as for the different body positions, and the different longwave and shortwave absorption coefficients considerably affect MRT results. As previously mentioned, the definition of longwave and shortwave radiation fluxes is the most critical aspect of MRT calculations. The sky and the scene (urban environment) are defined as the elements that play a significant role in longwave radiation exchanges.

The sky is defined by its degree of cloud cover, humidity and temperature, while the scene accuracy is measured by its capability to take into account buildings, freestanding objects, vegetation entities and ground elements. To take into account the whole shortwave radiation field, the type of sky and the definition of the urban scene are the relevant parameters. The calculation of sky and surface view factors are important in the determination of the whole radiation field by each simulation tool. Among the several methods available in the determination of view factors, the deterministic, the ray-tracing and the fisheye methods are the ones described in this tools comparison.

The capabilities of each tool to take into account local wind profiles, building profiles and evapotranspiration processes are also described, recognising them as parameters that significantly affect urban surface temperatures, which in turn affect MRT determination. CitySim Pro MRT calculation is based on the integral radiation measurement defined by Hoppe in 1992. The human body is customizable in its shape, position, shortwave absorption coefficient and longwave emissivity coefficient. Direct, diffuse from the sky and diffusely reflected shortwave radiations are taken into account. Longwave radiation exchanges with the sky and with the urban geometries are accounted. The type of sky is defined according to the Perez model, while the Perraudeau's index defines the degrees of cloud cover. Involved 3D surface temperatures are calculated, taking into account reciprocal radiation exchanges.

Buildings are defined following material properties and operation profiles. The ground is defined by its full stratigraphy and evaporation properties. The vegetation entities are accounted in respect to their evapotranspiration properties. Shading object is defined by their reflectance properties. Buildings, ground and vegetation objects take part of the whole radiation exchanges. The shading objects take part in the only shortwave radiation reflection. The wind profile is taken from .cli climate files derived from weather station measurements, available from Meteonorm.

Surface view factors and sky view factors are calculated with a deterministic method. CitySim Pro uses the Tregenza sky to divide the sky vault into 145 patches (which are each one divided into 100 further patches) of similar solid angle and the Perez all-weather model to calculate the radiance at the centroid of each patch. For surface view factors, views encapsulating the hemisphere are rendered from each surface centroid, with every surface having a unique colour. Each pixel is translated into angular coordinates to identify the corresponding patch as well as the angle of incidence (Robinson et al. 2009).

The specific equation of Bruse defines ENVI-met calculation of $M R T$. The human body is defined by a default shortwave absorption coefficient $\left(a_{k}=0.7\right)$ and longwave emissivity coefficient $\left(\varepsilon_{\mathrm{p}}=0.97\right)$. Direct, diffuse from the sky and diffuse reflected shortwave radiations are taken into account. The shortwave radiation diffused by the sky in cloudless conditions is estimated after Brown and Isfält (1974), meanwhile for cloudy sky conditions the direct shortwave radiation is reduced according to Taesler and Anderson (Taesler and Anderson, 1984, Ali Toudert, 2005). Longwave radiation exchanges with the sky and with the urban geometries are accounted. 3D surfaces are simplified following the ENVI-met orthogonal Arakawa C-grid and their temperatures are calculated with reciprocal radiation exchanges. Buildings are defined in accordance with material properties (stratigraphy up to three material) without operation profiles. Their surface temperatures are calculated by solving the energy balance equation for each surface, without taking into account the heat storage in the building materials (Ali Toudert, 2005).

The ground is defined in accordance of its stratigraphy $(5 \mathrm{~m}$ depth) and solved following Darcy's law taking into account evaporation, water exchange inside the soil and water uptake by plant roots (ENVI-met, 2017). The vegetation entities are accounted in respect of their transpiration properties. The vegetation model is coupled with the soil model, allowing the water transpired by the plant to be supplied by the soil. All plants are treated as individual species with an integrated water balance control and heat and water stress reaction concept. Freestanding objects are defined by their material properties (only PRO/SCIENCE version). Buildings, ground, vegetation and freestanding objects (only PRO/SCIENCE version) take part of the whole radiation exchanges. The wind profile is locally calculated with a full 3D Computational Fluid Dynamics model for each grid in space in each time step solving the Reynoldsaveraged non-hydrostatic Navier-Stokes equations (ENVI-met, 2017). View factors are calculated in a deterministic way with the Indexed View Sphere (IVS) method, in which each urban element is considered using its actual state regarding sun reflection and thermal radiation.

RayMan MRT calculation is based on the integral radiation measurement defined by Hoppe in 1992. The human body is defined by a default shortwave absorption coefficient $\left(a_{k}=0.7\right)$ and longwave emissivity coefficient $\left(\varepsilon_{\mathrm{p}}=0.97\right)$. The MRT measurement height is $1.1 \mathrm{~m}$ above the ground, which corresponds approximately to the level of the centre of gravity of a standing person. Direct and diffuse from the sky shortwave radiation can be both manually inputted as global radiation or further calculated by the model. Diffuse reflected shortwave radiation is taken into account by the ground element if the only fish-eye photo is used for the sky view factor calculation. Meanwhile buildings and trees are part of the calculation if modelled or imported as obstacle file inside the tool (Matzarakis et al., 2009). Longwave radiation exchanges are accounted for the sky, the ground and the building elements. The sky is defined by manual input of cloudiness, air temperature and humidity and solved following the Angstrom formula. Material properties are not taken into account. Buildings and ground entities are defined in accordance with their albedo and Bowen-ratio coefficients. The vegetation entities can be modelled including deciduous or coniferous trees. The ground and building elements take part of the whole radiation exchanges in a simplified way, as their reflection and emission properties are simplified as all equal. Vegetation objects are considered in respect of their only shading capabilities. The wind speed is manually inputted such as parameters like humidity, air temperature and cloud cover. Surface view factors and sky view factors are calculated with a fisheye image method. It calculates view factors from fish eye pictures or any other circular images with distinct obstacles. When obstacles are defined in the image, the sky pixels are calculated and related to the total number of pixels in the image. The value for each pixel is then weighted and normalized in order to get a sky view factor between zero and one.

Ladybug Tools MRT calculation is based on the determination of surface temperatures and their view factors (Mackey et al. 2017). A default shortwave absorption coefficient defines the human body $\left(a_{k}=0.67\right)$, longwave emissivity coefficient $\left(\varepsilon_{\mathrm{p}}=0.95\right)$ (Arens et al., 2015) and customizable in its position. Direct, diffuse from the sky and diffuse reflected shortwave radiations are taken into account. The sky can be defined as climate-based, standard CIE or cumulative sky. The cumulative 
sky matrix can be further customized as Tregenza sky or Reinhart sky. The only reflection that runs in the MRT calculations (and thus all the derived microclimatic maps) is the reflection off of the ground. Ladybug Tools, at the time of writing, does not include reflected solar off of buildings and free-standing objects in its calculations. This can be accounted for by adjusting the input of diffuse radiation to the SolarAdjusted temperature component. The scripts are thus more precise when façade are studied under cloudy skies.

Longwave radiation exchanges with the ground are accounted for, as well as with the sky. Longwave radiation exchanges with the sky are solved with the MENEX model (Blazejczyk, 2005). Complex 3D surface temperatures take part of the longwave radiation exchanges without taking into account reciprocal radiation exchanges (EnergyPlus, 2017). Buildings are defined in accordance with material properties and operation profiles. The ground is defined as EnergyPlus ground zone and defined by its reflectance. EnergyPlus includes objects to model evaporative heat transfer from vegetated surfaces, which can be used to account for grass, shrubs (EnergyPlus, 2017). The EnergyPlus evaporative heat transfer from vegetated surfaces model, can be used to account for longwave radiation exchanges with trees, which can also be defined as shading objects following their reflectance properties in a simplified model. Buildings, ground and vegetation entities take part in the whole radiation exchanges. The wind profile is taken from epw climate files, which are derived from weather station measurements. Detailed local wind profiles can be simulated with the Honeybee microclimate map and the use of the Butterfly plug-in.

Surface view factors and sky view factors are calculated with a Ray-tracing method. Involving a geometric simplification of the sky, it consists of shooting virtual rays from the calculation point through the midpoint of each sky dome polygon to determine potential intersections with the surfaces of the elevation model. The sky dome polygon is assumed to be entirely visible if no one elevation elements do not intercept the ray that passes through its midpoint. Autodesk CFD calculates outdoor comfort indexes based on Finite Element Methods (FEM), including MRT. Default values define the human body. Direct, diffuse from the sky and diffusely reflected shortwave radiation are taken into account. Autodesk CFD 2017 uses a diffuse grey body radiation model that has no wavelength and directional dependency, which lead to a simplification of the simulated diffusely reflected radiation. Longwave radiation exchanges with the sky and with the urban geometries are accounted.

Complex 3D surface temperatures are calculated, taking into account reciprocal radiation exchanges. Material properties and no operation profiles define buildings. The ground is defined in its material properties. The vegetation entities are defined as shading objects. Their material properties define the shading object. Buildings, ground and shading objects take part of the whole radiation exchanges. The wind profile is locally calculated with a full 3D Computational Fluid Dynamics model. Surface view factors and sky view factors are calculated with a deterministic method that enforces reciprocity between solids (Autodesk, 2016b).

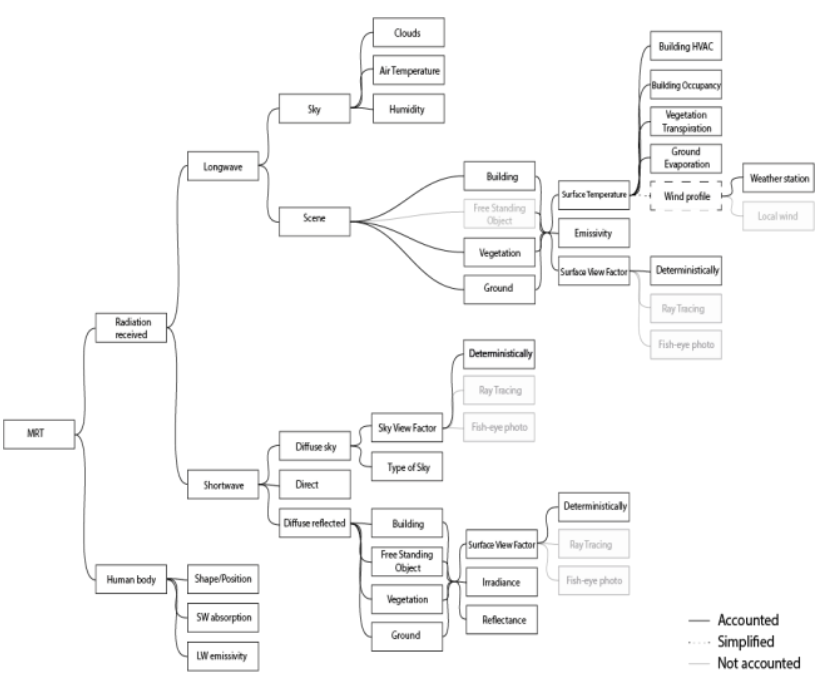

Figure 2: CitySim physical assumptions in the MRT calculation

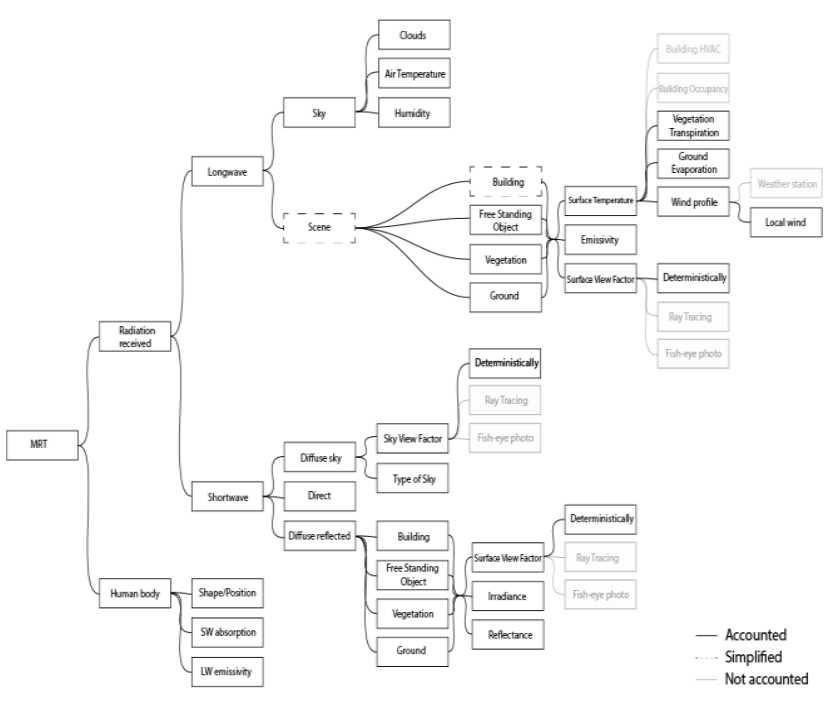

Figure 3: ENVI-met physical assumptions in the MRT calculation.

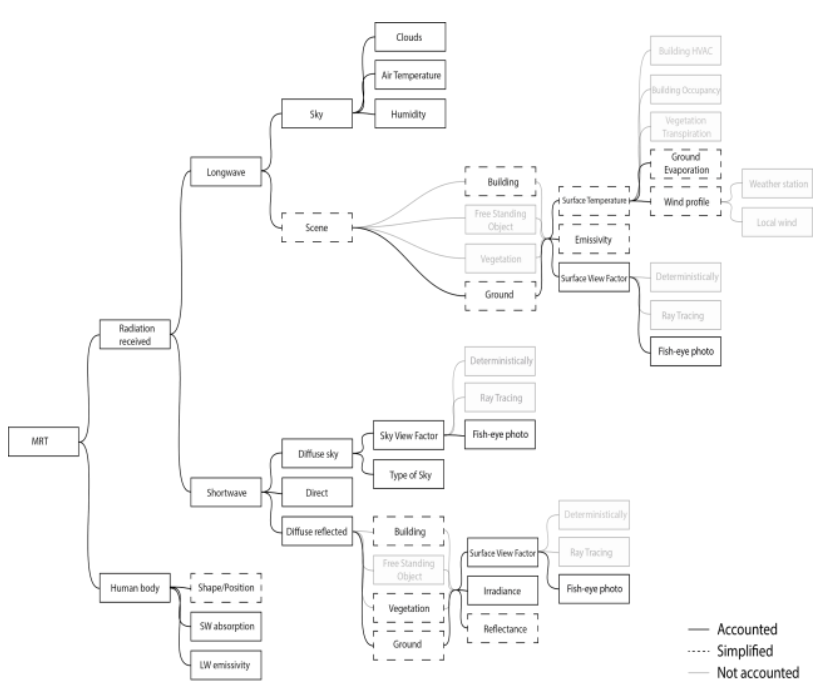

Figure 4: RayMan physical assumptions in the MRT calculation. 


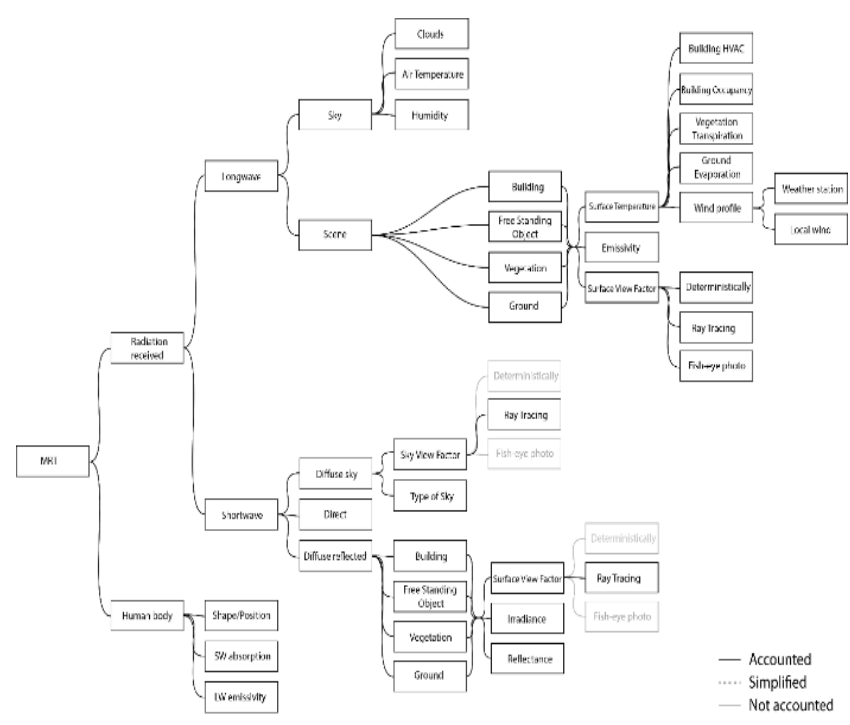

Figure 5: Ladybug Tool's physical assumptions in the MRT calculation.

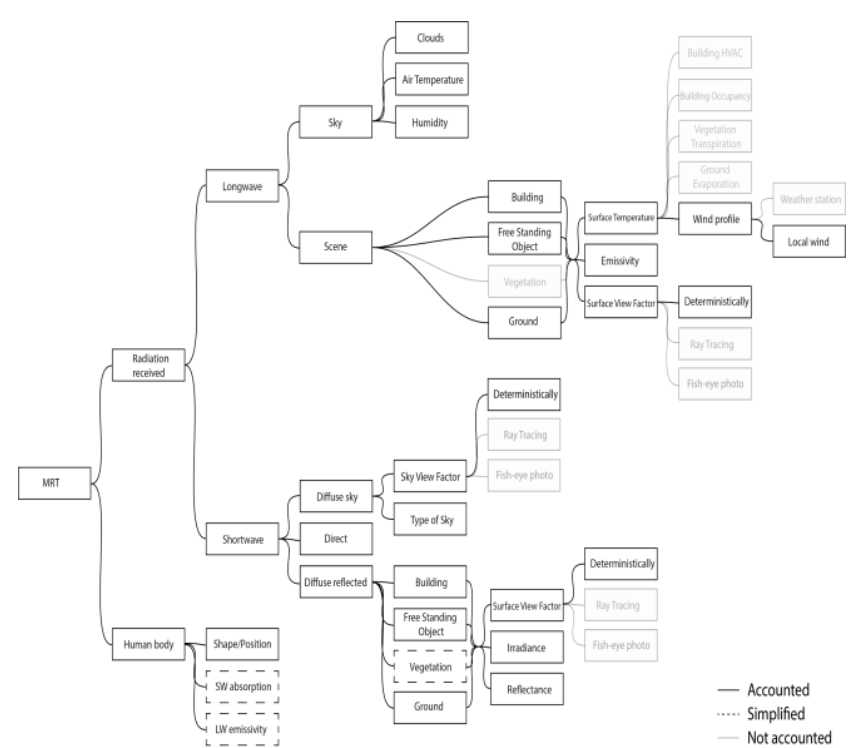

Figure 6: Autodesk CFD physical assumptions in the MRT calculation.

\section{Discussion}

A review of what tools take into account when predicting MRT is proposed in Table 1. The discussion follows the structure of the table.

Human Body. When different body definitions are relevant in the determination of MRT CitySim Pro, ENVI-met and Ladybug Tools are more accurate. CitySim Pro offers freedom in the customisation of position, grid definition and coefficient of absorption. The RayMan tool performs MRT simulations at height $1.1 \mathrm{~m}$ above the ground, being suitable for simulations based on standing person perception. ENVI-met and Ladybug Tools have the capabilities to determine MRT results at a different height above the ground. They provide default absorption coefficients, which are customizable by users through the script code. Autodesk CFD model has no wavelength and directional dependency, thus simplifying the absorption of the longwave and shortwave radiation fields.
Shortwave radiation field. When shortwave radiation fluxes have great importance, CitySim Pro, Ladybug Tools and ENVImet take into account direct, diffuse and reflected radiation by buildings, free-standing objects, vegetation entities and ground. RayMan allows defining one albedo value for the whole urban geometry, simplifying the diffusely reflected radiation fluxes. Autodesk CFD simplifies the role of vegetation entities, modelling them as freestanding objects.

Longwave radiation field. When longwave radiation fluxes play a significant role in the determination of surface temperatures, which affect MRT values, ENVI-met is the tool that provides the best accuracy. It allows taking into account local wind profiles, reciprocity between buildings, ground evaporation, vegetation transpiration and water bodies affections. Longwave radiation exchange for freestanding objects is allowed in the PRO/SCIENCE version of the software. RayMan simplifies the radiation fields by assigning to the surrounding environment one universal emissivity value. Ladybug Tools accounts for reciprocity between buildings, takes into account freestanding objects, and model the ground as an EnergyPlus thermal zone. Autodesk CFD is suitable for a contest where ground evaporation and vegetation transpiration do not play a key role, as these features are not taken into account by the model.

When the design site is significantly affected by high wind profiles, ENVI-met and Autodesk CFD are the tools that have to be considered as more suitable. Their 3D Computational Fluid Dynamics model provides accurate local wind profiles. CitySim Pro and Ladybug Tools perform their simulation under wind profiles recorded by weather stations. Ladybug Tools allow simulating detailed local wind profiles with the use of the Butterfly plug-in. RayMan requires wind speed as an input parameter for its simulations.

View Factors calculation. The definition of the sky and surface view factors play a crucial role in the determination of the whole radiation field. Here CitySim Pro, ENVI-met and Autodesk CFD are the tools that provide the best accuracy due to their deterministic calculation method. CitySim Pro uses a deterministic method that divides the sky vault into 145 patches, which are divided into 100 further patches. ENVI-met view factors are calculated with the new Indexed View Sphere (IVS) method, in which each urban element is considered. Autodesk CFD uses a true view factor that enforces reciprocity between solids. Ladybug tools view factor calculation is based on the raytracing capabilities of shooting virtual rays from the calculation point through the midpoint of each skydome polygon. The accuracy of this method increases when the size of the skydome polygons diminishes, as the polygons become closer to a differential area and the shape of the skydome closer to a hemisphere. The accuracy of this method is thus dependent on the number of rays that are sent to the dome. The number of rays can be defined concerning accuracy and simulation time. RayMan uses a fisheye method that calculates the sky and the obstruction entities by counting the pixels of the digitised image. The calculation of the view factors is thus related to the almost 480x480 pixel definition of the image, providing a quick but not accurate as of the other tools calculation.

\section{Conclusion}

Researchers and practitioners move toward the modelling of outdoor microclimate and comfort conditions. Due to the complexity of urban environments, understanding software tools capabilities of determining comfort indices and physical parameters is key. Several comfort indices as Predicted Mean Vote (PMV), Physiologically Equivalent Temperature (PET) and Universal Thermal Climate Index (UTCI) have been introduced to the design practised. As a relevant parameter for 
all of the mentioned comfort indices, new attention is given to MRT. Potential users are confronted with a lack of information about the tools' assumptions when accounting MRT and related comfort indices. Therefore, this paper aims to highlight the different physical assumptions that known simulation tools use in determining MRT. The paper, filling a gap in the existing literature, has collected and organised this information focusing on MRT equations and calculation assumptions. It is shown that depending on the type of site (shortwave dominated, longwave dominated, or wind dominated) some tools should be used and certain others avoided. The research thus provides urban planners, designers and researchers with key information that would drive them in selecting the appropriate simulation tool.

Table 1: Comparison of outdoor variables and software data

\begin{tabular}{|c|c|c|c|c|c|}
\hline & CitySim Pro & ENVI-met & RayMan & Ladybug Tools & Autodesk CFD \\
\hline \multicolumn{6}{|l|}{$\begin{array}{l}\text { Human Body Radiation } \\
\text { Exchange }\end{array}$} \\
\hline Shape/Position & Accounted & Accounted & Simplified & Accounted & Accounted \\
\hline Shortwave absorption & Accounted) & Accounted & Accounted & Accounted & Simplified \\
\hline Longwave emissivity & Accounted & Accounted & Accounted & Accounted & Simplified \\
\hline \multicolumn{6}{|l|}{ Shortwave Radiation } \\
\hline Direct radiation & Accounted & Accounted & Accounted & Accounted & Accounted \\
\hline Diffuse sky radiation & Accounted & Accounted & Accounted & Accounted & Accounted \\
\hline $\begin{array}{l}\text { Diffuse reflected radiation } \\
\text { (Buildings) }\end{array}$ & Accounted & Accounted & Simplified & Simplified & Accounted \\
\hline $\begin{array}{l}\text { Diffuse reflected radiation (Free } \\
\text { standing objects) }\end{array}$ & Accounted & Accounted & Not accounted & Not Accounted & Accounted \\
\hline $\begin{array}{l}\text { Diffuse reflected radiation } \\
\text { (Vegetation) }\end{array}$ & Accounted & Accounted & Simplified & Accounted & Simplified \\
\hline $\begin{array}{l}\text { Diffuse reflected radiation } \\
\text { (Ground) }\end{array}$ & Accounted & Accounted & Simplified & Simplified & Accounted \\
\hline Sky view factor & Deterministically & Deterministically & Fish-eye photo & Ray Tracing & Deterministically \\
\hline Surface view factor & Deterministically & Deterministically & Fish-eye photo & Ray Tracing & Deterministically \\
\hline \multicolumn{6}{|l|}{ Longwave Radiation } \\
\hline $\begin{array}{l}\text { Longwave radiation exchange } \\
\text { with the sky }\end{array}$ & Accounted & Accounted & Accounted & Accounted & Accounted \\
\hline Longwave radiation (Buildings) & Accounted & Accounted) & Simplified & Accounted & Accounted \\
\hline $\begin{array}{l}\text { Longwave radiation } \\
\text { (Freestanding objects) }\end{array}$ & Not accounted & Accounted & Not accounted & Accounted & Accounted \\
\hline Longwave radiation (Vegetation) & Accounted & Accounted & Not accounted & Accounted & Not accounted \\
\hline Longwave radiation (Ground) & Accounted) & Accounted & Simplified & Accounted & Accounted \\
\hline Transpiration (Vegetation) & Accounted & Accounted & Not accounted & Not accounted & Not accounted \\
\hline Evaporation (Ground) & Accounted & Accounted & Simplified & Not accounted & Not Accounted \\
\hline Local Wind Speed & Not accounted & Accounted & Not accounted & Accounted & Accounted \\
\hline Local Wind Direction & Not accounted & Accounted & Not accounted & Accounted & Accounted \\
\hline Sky view factor & Deterministically & Deterministically & Fish-eye photo & Ray Tracing & Deterministically \\
\hline Surface view factor & Deterministically & Deterministically & Fish-eye photo & Ray Tracing & Deterministically \\
\hline
\end{tabular}

\section{References}

Al-Sudani A, Hussein H, Sharples S (2017) Sky View Factor Calculation. A computational-geometrical approach, Space Syntac and Ontologies - Volume 2 eCAADe35 p.673, eECAADe 2017 35th Conference, Rome 20th-22nd September 2017, p.673-682.

Ali-Toudert F (2005) Dependence of Outdoor Thermal Comfort on Street Design in Hot and Dry Climate, Dissertation Faculty of Environment and Natural Resources, University of Freiburg, ISSN 1435-618X.

Arens . Hoyt T. Zhou X. Huang L. Zhang H. Schiavon F. (2015) Modeling the comfort effect of short-wave solar radiation indoors, Building and Environment, Volume 88, p.3-9

ASCE (2004) Outdoor Human Comfort and Its Assessment, State of the Art, SCE ISBN: 9780784406847

ASHRAE (2001) ASHRAE Fundamentals Handbook 2001 (SI Edition) American Society of Heating, Refrigerating, and Air-Conditioning Engineers, ASHRAE ISBN 9781883413880

Autodesk (2016a) What's New in Autodesk® CFD 2016. http://help.autodesk.com/view/SCDSE/2017/ENU/?guid=GUIDA27F10AE-67C6-45CB-959F-0F2074F4D131. (last visit December 7, 2016)
Autodesk (2016b) Autodesk CFD radiation model. https://knowledge.autodesk.com/support/cfd/learn-

explore/caas/CloudHelp/cloudhelp/2014/ENU/SimCFD/files/GUIDE532C49F-8EEC-4B56-B7B6-79B31F0D5115-htm.html. (last visit December 7, 2016).

Autodesk (2017) MRT Equation https://forums.autodesk.com/t5/cfd-forum/mrtequation/m-p/6915691\#M14341 2017a. (last visit April 1, 2017).

Blazejczyk K (1992) MENEX· Man-Environment Heat Exchange Model and its Applications in Bioclimatology. Proceedings of the Fifth Int. Conf. on Environmental Ergonomics

Blazejczyk K (2005) New indices to assess thermal risks outdoors. In: Holmér I, Kuklane K, Gao Ch (eds), Environmental Ergonomics XI, Proc. Of the 11th International Conference, 22-26 May, 2005 Ystat, Sweden, pp 222-225

Brown G. Isfält (1974) E. Solinstrålning och solavskärmning : Solar irradiation and sun shading devices, Rapport / Byggforskningen, 0346-5616; 1974:19. Stockholm: Statens inst. för byggnadsforskning

Brown M, Grimmond S, Ratti C (2001) Comparison of methodologies for computing sky view factor in urban environments, Proceedings of the 2001 International Symposium on Environmental Hydraulics

Bruse M (2004) ENVI-met 3.0: Updated Model Overview, 2004; pp.1-12. 
Bruse M. (1999) Die Auswirkungen kleinskaliger Umweltgestaltung auf das Mikroklima Entwicklung des prognostischen numerischen Modells ENVImet zur Simulation der Wind-, Temperatur- und Feuchteverteilung in städtischen Strukturen.

Chatzidimitriou A, Yannas S (2017) Street canyon design and improvement potential for urban open spaces; the influence of canyon aspect ratio and orientation on microclimate and outdoor comfort, Sustainable Cities and Society, Volume 33, August, p.85-101

Coccolo S, Mauree D, Naboni E, Kaempf J, Scartezzini J.-L. (2017) On the impact of the wind speed on the outdoor human comfort: a sensitivity analysis, Energy Procedia, Volume 122, September, p.481-486

Coccolo S. Kampf J. Scartezzini J.L. (2013) Design in the desert. A bioclimatic project with urban energy modelling. 2013, Proceeding of BS2013, Coccolo S. Kampf J. Scartezzini J.L. (2013) Design in the desert. A bioclimatic project with urban energy modelling. 2013, p.129-134

Coccolo S. Kampf J. Scartezzini J.L. Pearlmutter D. (2016) Outdoor human comfort and thermal stress: A comprehensive review on models and standards, Urban Climate, Volume 18, December, p.33-57

EnergyPlus (2017) Engineering Reference - EnergyPlus Documentation https://energyplus.net/sites/default/files/pdfs_v8.3.0/EngineeringReference.p df

ENVI-met. ENVI-met Model Architecture http://www.model.envimet.com/hg2e/doku.php?id=intro:modelconept

Epstein Y, Moran DS. Thermal comfort and heat stress indices. Industrial Health, 2006

Fanger P.O (1972) Thermal Comfort. McGraw Hill CityBook, New York, USA

Givoni, B., M. Noguchi, H. Saaroni, O. Pochter, Y. Yaacov, N. Feller \& S. Becker (2003): Outdoor comfort research issues. Energy Buildings 35(1): 77-86.

Hoppe P. (2002) Different aspects of assessing indoor and outdoor thermal comfort. Energy and Buildings 34, 2002. pp 661-665.

Höppe, P., (1992). A new procedure to determine the mean radiant temperature outdoors. Wetter und Leben, Volume 44, p.147-51

ISO 7726 Ergonomics of the thermal environment -- Instruments for measuring physical quantities

Jeong D, Park K, Song B, Kim G, Choi C, Moon B (2015) Validation of ENVImet PMV values by in-situ measurements. Toulouse, France

Johansson E, Thorsson S, Emmanuel R, Kruger E, (2014) Instrument and methods in outdoor thermal comfort studies - the need fo standardization, Urban Climate, V.10, p.346-366

Johnson GT and Watson ID (1984) The determination of view factors in urban canyons, Journal. Clim. Moreover, Appl.Meteor., 2, 329-335.

Kantor N. Unger J. (2011) The most problematic variable in the course of humanbiometeorological comfort assessment - the mean radiant temperature. Central European Journal of Geosciences, Cent. Eur. J. Geosci. Volume 3(1), p. $90-100$

Lai A, Maing M, Ng E (2017) Observational studies of mean radiant temperature across different outdoor spaces under shaded conditions in densely built environment, Building and Environment, Volume 114, March 2017, Pages 397-409

Lindberg F, Holmer B, Thorsson S, Rayner D. (2013) Characteristics of the mean radiant temperature in high latitude cities-implications for sensitive climate planning applications. Int J Biometeorol 58, p. 613-627.

Mackey C, Galanos T, Norford L, Roudsari MS (2017) Wind, Sun, Surface Temperature, and Heat Island: Critical Variables for High-Resolution Outdoor Thermal Comfort, Climate, MDPI Climate 2017, Volume 5, p.59-80

Matzarakis A. (2002) Validation of Modelled Mean Radiant Temperature Within Urban Structures, Conference on Agricultural and Forest Meteorology - 12th joint conference on the applications of air pollution meteorology with - Fourth symposium on the urban environment, AMS, 172-173

Matzarakis A. (2006) Estimation and Calculation of the Mean Radiant Temperature Within Urban Structures, n: Biometeorology and Urban Climatology at the Turn of the Millenium (ed. by R.J. de Dear, J.D. Kalma, T.R. Oke and A. Auliciems): Selected Papers from the Conference ICBICUC'99, Sydney, WCASP-50, WMO/TD No. 1026, 273-278

Matzarakis A. Rutz F. Mayer H. (2009) Modelling radiation fluxes in simple and complex environments: basics of the RayMan model, International Journal of Biometeorology 51, 323-334

Mayer H (1993) Urban bioclimatology. Experientia, November 1993, Volume 49, Issue 11, pp 957-963

Mayer H, Hoppe $P$ (1987) Thermal comfort $f$ mann in different urban environments. Theor.Appl. Climatol. 38 p.43-49.

Mauree, Dasaraden, Emanuele Naboni, Silvia Coccolo, A. T. D. Perera, Vahid M. Nik, and Jean-Louis Scartezzini. "A Review of Assessment Methods for the Urban Environment and Its Energy Sustainability to Guarantee Climate Adaptation of Future Cities." Renewable and Sustainable Energy Reviews 112 (September 1, 2019): 733-46. https://doi.org/10.1016/j.rser.2019.06.005.
Mauree, Dasaraden, Daniel Sang-Hoon Lee, Emanuele Naboni, Silvia Coccolo, and Jean-Louis Scartezzini. 2017. "Localized Meteorological Variables Influence at the Early Design Stage.” Energy Procedia, CISBAT 2017 International Conference Future Buildings \& Districts - Energy Efficiency from Nano to Urban Scale, 122 (Supplement C):325-30. ISSN: 18766102 https://doi.org/10.1016/j.egypro.2017.07.331

Naboni E, Meloni M, Coccolo S, Kaempf J, Scartezzini J-L (2017) An overview of simulation tools for predicting the mean radiant temperature in an outdoor space, Energy Procedia, Volume 122, September, p.1111-1116

Naboni, Emanuele, Jonathan Natanian, Giambattista Brizzi, Pietro Florio, Ata Chokhachian, Theodoros Galanos, and Parag Rastogi. "A Digital Workflow to Quantify Regenerative Urban Design in the Context of a Changing Climate." Renewable and Sustainable Energy Reviews 113 (October 1, 2019): 109255. https://doi.org/10.1016/j.rser.2019.109255.

Naboni E, Danzo E, Ofria LA Parametric Workflow to Conceive Facades as Indoor and Outdoor Climate Givers (2019) SimAUD, Atlanta.

ONU (2014) World Urbanisation Prospects. New York, United, p.32.

Park S, Tuller SE, Jo M (2014) Application of Universal Thermal Climate Index (UTCI) for microclimatic analysis in urban thermal environments, Landscape and Urban Planning, Volume 125, May 2014, p.146-155

Robinson D, Haldi F, Kämpf J, Leroux P, Perez D, Rasheed A, Wilke U. (2009) CitySim: Comprehensive micro-simulation of resource flows for Sustainable Urban planning. BS2009 Proceedings, Glasgow, Scotland, pp.1083-1090.

Roudsari M., Pak M. Ladybug (2013) A parametric environmental plugin for Grasshopper to help designers create an environmentally-conscious design, Proceedings of BS2013, 13th Conference of International Building Performance Simulation Association, Chambery, France, August 26-28, p.3128-3135

Santamouris M (2013) Using cool pavements as a mitigation strategy to fight urban heat island - A review of the actual developments, Renewable and Sustainable Energy Revies, Volume 26, p.224-240

Taesler R. Anderson C. (1984) A method for solar radiation computings using routine meteorological observations, Energy and Buildings, 7, p. 341-352

Thorsson S, Lindberg F, Eliasson I, Holmer B (2007) Different methods for estimating the mean radiant temperature in an outdoor urban setting. Int. J. Climatol. 27, 1983-1993. doi:10.1002/joc

Thorsson S, Rocklöv J, Konarska J, Lindberg F, Holmer B, Dousset B, Rayner D (2014) Mean radiant temperature - a predictor of heat related mortality. Urban Climate, 10(Part 2) p.332-345.

VDI (1998) VDI 3789, Part 2: Environmental meteorology, methods for the human biometeorological evaluation of climate and air quality for the urban and regional planning at regional level. Part I: Climate. VDI/DIN- Handbuch Reinhaltung der Luft, Band 1b, Düsseldorf.

VDI (2008) 4878 Part 2, Environmental Meteorology - Methods for the Human Biometeorological Evaluation of Climate and Air Quality of Urna and Regional Planning at Regional Leve; Part I: Climate Beuth Verlag, Berlin.

Wu J, Zhang Y, Meng Q (2013) Calculation method of sky view factor based on rhino-grasshopper platform, Proceedings of BS 2013: 13th Conference of the International Building Performance Simulation Association, Chambéry, France, pp. 2658-266 